\title{
Assessment of the technological potential of fuel enterprises and their production system
}

\author{
Alexander Rementsov ${ }^{1}$, Natalia Lebedeva ${ }^{2}$, and Olga Kirichenko, ${ }^{2, *}$ \\ ${ }^{1}$ Association of Innovative Regions of Russia, 12, Presnenskaya nab., 123112, Moscow, Russia \\ ${ }^{2}$ Financial University under the Government of the Russian Federation, 49, Leningradskiy pr-t, \\ 125167, Moscow, Russia
}

\begin{abstract}
The article describes its own methodology for determining indicators, based on the analysis of standard and specific indicators for the enterprises of fuel and energy complex. The article is devoted to the consideration of modern approaches to the definition of the concept "production and technological potential of organizations of the fuel and energy complex of the Russian Federation". The article touches upon some topical issues of effective management of the use and development of the TEC enterprise production potential. The study uses several approaches: generalization, systematization, formalization, logical, formal methods, as well as comparative analysis methods to study modern approaches to the definition of the studied concept. The tasks considered in the article are theoretical. The economic content of the concept of production and technological potential of the fuel and energy complex and the production system is disclosed. The article presents current economic content of the concept of production and technological potential of energy companies based on a review of modern approaches to the definition of this concept, as well as indicators for the implementation of the production system.
\end{abstract}

\section{Introduction}

In modern market conditions, enterprises of the fuel and energy complex (FEC) have many requirements, for the most of them the Russian fuel and energy complex is not ready. It is required not only to produce competitive products, but also to systematically update them and provide appropriate service in accordance with market requirements, use production resources; provide progressive systematic improvement of the means of production, technological processes, methods of labor organization; use automated management systems along with ensuring a high standard of living and working conditions for employees of enterprises.

In existing realities, the majority of energy companies have outdated fixed assets, a lack of technology in management processes and production, a drain of human capital to the leading global markets.

\footnotetext{
* Corresponding author: OSKirichenko@fa.ru
} 


\section{Materials and methods}

The study uses several approaches: generalization, systematization, formalization, logical, formal methods, as well as comparative analysis methods to study modern approaches to the definition of the studied concept. The tasks considered in the article are theoretical.

Currently, there is no consensus on the fact that it represents the production potential and what methods are effective for its entire study.

Unpredictable behavior of individual components of the production potential in unstable conditions of the economic environment, the assessment of the effectiveness of their use in the production process is stochastic and could be determined by statistical methods.

Analyzing the economic literature, we can conclude that there are two main approaches in determining the productive potential: resource and productive.

The first scientist who defined production potential was A. I. Anchishkin, in his opinion, production potential is a set of resources that take the form of production factors in the production process.

The resource concept distinguishes two points of view on the problem under study. The first direction (Savitskaya G.V., Abalkin L.I., Lukinov I.V., Zolotarev V.A., Volik I.N.) by the production potential understand the totality of resources, not taking into account their interconnection and interaction in the production process. The disadvantage of this approach can be considered that the availability of resources does not mean their compatibility and usability (applicability).

In the framework of the "second resource approach", it is understood that resources that make up the production potential are considered in the context of their ability to produce material goods. Thus, according to Gunina I.A., one can speak not only about expanding the concept of "production potential", but also its systematic interpretation.

Some economists describe the production potential as one of the components of macroeconomic indicators of the functioning of the national economy. In general, interest boils down to the number of products (work, services) that a single industry or state can produce with full use of available resources.

Analyzing all of the above, it can be determined that production potential is an indicator characterizing the ability of an enterprise to obtain the highest possible production result and achieve strategic goals, determined by the totality of all available resources and the possibility of their optimal transformation into a competitive product, with various options for interacting with internal and the external environment of the enterprise.

\section{Results}

Russian fuel and energy companies highly need development related to the introduction of digital technologies to increase the observability and controllability of the electric grid complex, while at the same time bringing operational and investment efficiency on a new level.

An objective assessment of the capabilities of fuel and energy companies, parameters and characteristics of their technical potential are key indicators in making timely economic, technical and social decisions for current and faster development. [1]

Analyzed studies suggesting that the approaches and methods presented in Russia and on the global arena to assessing the technical potential of enterprises, are very limited and need appropriate additions and adjustments.

Technological potential (TP) is a complex of available, attracted and mobilized resources - labor, information, financial, material, technical, organizational and managerial resources to achieve the goals of scientific and technological development. 
The technological potential is formed by various entities - enterprises, organizations, state and municipal institutions - through investment, the creation of scientific and technological developments. The economic development of the entire region, necessary for the optimal functioning of the above system, depends on the level of development of the TP of an individual fuel and energy complex. [2]

The need to determine the category of "technological potential" at the level of the main link of the economy - the enterprise - is obvious primarily from the standpoint of increasing the efficiency of its use at all levels of production. [3]

An initial assessment of the technological potential of an enterprise can be carried out using a technological audit, which is: under the audit (from the English. Audit verification, revision) in the general sense we understand the process of accumulation and evaluation of large amounts of information related to a particular economic system or business entity with the purpose of establishing compliance with certain criteria or standards.

One mode definition is that the technological audit is the process of assessing the current technological potential of enterprise and its internal procedures. It is also a process of identifying strengths and weaknesses of businesses in order to restructure or implement more advanced solutions.

A technology audit itself is part of an operational audit; in addition, the organization is audited for compliance and audited financial statements.

Performing a technological audit in an organization is a rather complicated procedure, since the effectiveness of operations is more difficult to objectively evaluate than the compliance of financial statements with generally accepted national or international financial reporting standards. It can be assumed that the technological audit has a great similarity in procedure with consulting operations.

When comparing a technology audit with a financial audit, the following feature can be noted: a financial audit is aimed at reflecting business transactions in the financial statements, a technology audit is aimed at determining the productivity and efficiency of operations.

The next difference is that the financial audit is time-oriented to past events, (retrospective nature), the technological audit in its purpose is focused on the future activities of the organization. [4]

The process of conducting a technological audit in general has three main stages. [5]

An overview of the technologies used by the organization and an analysis of the organization's position regarding the application of existing technologies.
Overview of technologies used in the industry and competing organizations, and identification of technological standards

A comparison of the technologies used in the organization

with the identified technological standards for evaluating

the effectiveness and prospects (the analysis of the

technological portfolio of the organization is carried out)

Fig. 1. Procedure for conducting a technological audit on enlarged units.

When planning production systems, many enterprises use outdated information and standards, for example, books on practical implementation of the Toyota Production System, etc., which create additional limit during the implementation of the planned approach. 
Due to lack of information, enterprises learn from their own mistakes and therefore not every player in the market is ready to proceed with implementation. A wide range of enterprises is focused on data on foreign production systems that have not been updated for many decades. Over the past time, the concept of Production Systems has gone a few steps forward, and global manufacturers are already focused on completely different tasks.

An important characteristic feature of the production potential is the interchangeability and alternative nature of its elements. The effective replacement of one of its elements with another is one of the most important problems in the operational management of the production process. Changes occurring in any one element of the production potential require a change in its other elements.

The constituent elements that affect the successful use of the production potential of the enterprise are shown in Figure 2.

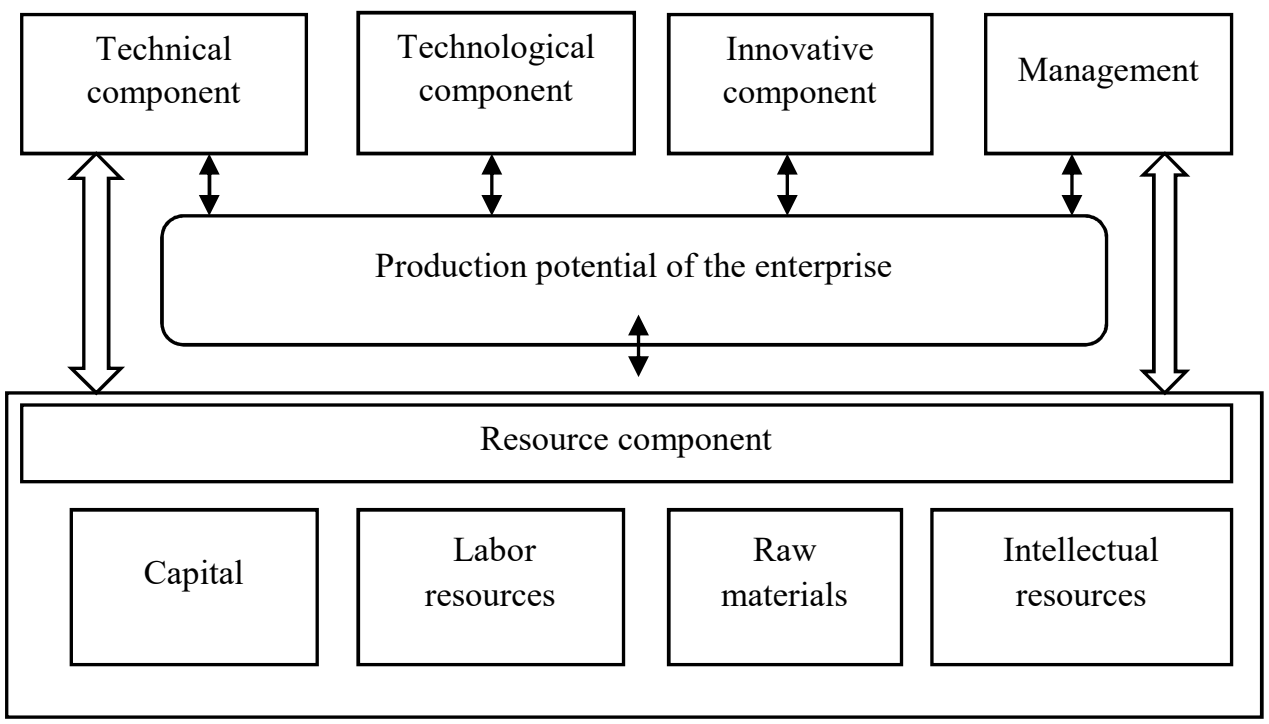

Fig. 2. Elements of the production potential of the enterprise.

The interchangeability of elements of production potential is one of its most studied characteristics. Issues of replacing living labor with the active part of the basic production assets were actively studied. For example, the saving of living labor as part of the development of the active part of fixed assets can be regulated using the ratio of $\mathrm{A}$. Tolkachev:

$$
\Pi=\frac{\underline{\mathrm{P}}_{1}}{\mathrm{~S}_{1}-\mathrm{P}_{0}-1}
$$

where $\Pi$ is the replacement coefficient of living labor by elements of fixed assets; P0, P1 - labor productivity, respectively, before and after the replacement; S0, S1 respectively, the capital-labor ratio of labor in these periods. In this case, by setting the threshold value $\Pi *$ of the replacement coefficient $\Pi$, it is possible to determine the values of the indicators $\mathrm{P} 1$ and $\mathrm{S}$ so that for the actual value the replacement coefficient of living labor by the elements of the basic production assets of the $\Pi_{\mathrm{F}}$ fulfills the condition: " $\Pi_{\mathrm{F}}$ $\geq \Pi *$ ".

It should be borne in mind that the interchangeability of elements of the production potential should not be understood purely mechanically, although it is based on the technical and technological features of production. The interchangeability of elements of production potential is a greater economic problem. Therefore, under market conditions, as 
the main criterion for the interchangeability of potential elements, additional profit should be considered by reducing production costs.

The degree of alternativeness of the elements of the production potential is a variable and depends on the situation prevailing in the economic environment of the joint venture. It changes, for example, depending on the level of development of the production potential, as well as on the features of the economic system: the scale, nature of the activity and the degree of its isolation.

The solution to the problem of interchangeability of production potential elements ultimately boils down to determining whether it is economically feasible to replace one element of the production potential with another element. If such a replacement brings additional profit, then in what proportions does it occur, what are the features of such a replacement and whether there are conditions for it, and what are the consequences of the replacement to develop the production potential.

The development of the concept of modern production systems is influenced by international cooperation and modern challenges that globalization poses to manufacturers. Therefore, to the established concepts of quality, added value, lean production, minimization of losses, new trends are added - global production, energy efficiency, value chains and environmental friendliness.

It could be argued that only those enterprises that are moving towards the development of TOYOTA PRODUCTION SYSTEM standards implement and develop the Production System. But we want to emphasize that all the tools, methods, practices, approaches, philosophies and concepts of development, management and optimization of production as a result of the evolution of production management practices (organization of production) are included in the concept of Production systems. [6]

In Russia, there are about 500 enterprises that over the past 5 years have consistently introduced modern management and production management systems, although, in fact, there are probably more of these enterprises, since it is difficult to determine the exact number of enterprises, corporations, holdings, groups of companies which are undergoing real changes (GAZ, KAMAZ, RUSAL, ROSATOM, Russian Railways, OMK, EVRAZ, KTZ, RKTM and others).

The introduction of the Production System allows enterprises to increase competitiveness, ensure efficient and safe production at oil-producing enterprises, and enhance the professional competencies of workers and improve their working conditions and social conditions. [7]

To achieve these goals, four directions can be distinguished:

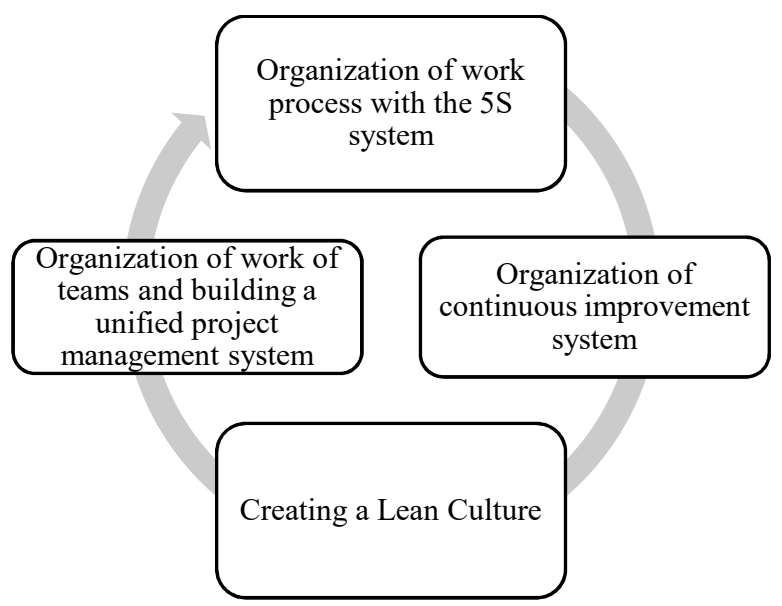

Fig. 3. Directions for the implementation of the production system. 
The complex structural and component composition of the production potential and the special importance of taking into account the interconnection of its elements require the development of methods for assessing and accounting for qualitatively heterogeneous resources in order to establish their resulting value for any ratios of structural elements (resources). We systematized theoretical and methodological issues of assessing the production potential of TEC enterprises. The study of methods for assessing production potential made it possible to identify the main areas, their advantages and disadvantages (table 1) [8].

Table 1. Approaches to the assessment of production potential.

\begin{tabular}{|c|c|c|c|c|}
\hline $\begin{array}{l}\text { Assessment } \\
\text { Approaches }\end{array}$ & $\begin{array}{c}\text { Rating } \\
\text { Type }\end{array}$ & $\begin{array}{c}\text { Brief } \\
\text { description }\end{array}$ & Advantages & Disadvantages \\
\hline Expert & Quality & $\begin{array}{l}\text { Analysis of } \\
\text { structural } \\
\text { components in } \\
\text { the form of } \\
\text { interviewing, } \\
\text { questioning }\end{array}$ & $\begin{array}{l}\text { They are used when } \\
\text { indicators cannot be } \\
\text { quantified or when it } \\
\text { is necessary to take } \\
\text { into account the } \\
\text { influence of certain } \\
\text { qualitative factors. }\end{array}$ & $\begin{array}{l}\text { The reliability of } \\
\text { the assessment is } \\
\text { determined by the } \\
\text { competence of } \\
\text { experts, the } \\
\text { assessment may be } \\
\text { subjective }\end{array}$ \\
\hline Resource & \multirow{2}{*}{ Quantitative } & \multirow{2}{*}{$\begin{array}{l}\text { The amount of } \\
\text { expended } \\
\text { resources in } \\
\text { production is } \\
\text { determined. } \\
\text { The essence of } \\
\text { production } \\
\text { potential is } \\
\text { defined as } \\
\text { potential } \\
\text { economic } \\
\text { result. }\end{array}$} & \multirow{2}{*}{$\begin{array}{l}\text { They give a } \\
\text { quantitative idea of } \\
\text { the object under } \\
\text { study, allow you to } \\
\text { determine the effect } \\
\text { of each element in the } \\
\text { composition of the } \\
\text { production potential } \\
\text { (the specific gravity } \\
\text { of each component of } \\
\text { the potential is } \\
\text { determined) }\end{array}$} & $\begin{array}{c}\text { They make it } \\
\text { impossible to take } \\
\text { into account } \\
\text { qualitative changes } \\
\text { in the structure of } \\
\text { potential }\end{array}$ \\
\hline Effective & & & & \\
\hline
\end{tabular}

There are two approaches to the study of production potential based on quantitative assessment: resource and productive.

The resource approach in the concept of production potential has become quite widespread in the works of Russian scientists and economists. At the same time, two "resource positions" are clearly distinguished:

1) production potential - a set of resources without taking into account their real relationships that develop in the production process;

2) production potential - this is production resources, quantitative and qualitative parameters that determine the maximum capacity for production at any given moment [9].

Profitable and combined approaches to diagnosing the organization's potential in market conditions are sometimes called productive in the scientific literature. Assessing the organization's potential when implementing one or another effective approach is carried out in the direction from the "output" of the production system to its "input", that is, changes in supply and demand on the market for this product are initially assessed, the phase of the product's life cycle and the organization's position in relation to its main competitors, indicators are calculated that characterize the process of capitalization in the industry, etc., and only then the possible return on assets held by the organization is evaluated [10]. 


\section{Conclusions}

Thus, we can conclude that the theory of the production potential of the enterprise is currently at the level of the formation of general directions and concepts. The lack of methodological foundations for assessing the production potential of an enterprise makes research in this area particularly relevant and promising. As a result, combining the presented directions of assessing the production potential of an enterprise, we can distinguish a set of potentials (as separate types of resources and results) that form a single comprehensive concept of "production potential of an enterprise".

Moreover, we can add that a characteristic feature of production potential is its ability to perceive the latest achievements of scientific and technological progress. A feature of the development of the production potential of a construction enterprise as a complex system is that its power, the flexibility of the internal structure of the elements, as well as the forms of interconnections between them, have a definite effect on the return on the production potential as a whole, on its ability to develop through direct and systematic use of new scientific achievements [11].

For example, the development and implementation of new technology goes through overcoming the one used. Therefore, it is extremely important to ensure high continuity of material, information, human and other factors of production when introducing new production technologies. This feature of production potential today is almost unexplored. However, in practice it has been proved that production less susceptible to scientific and technological progress is generally less efficient than production with a higher scientific and technical capacity, i.e., the ability to use the latest achievements of scientific and technological progress [12].

In conclusion, it should be noted that various characteristics of the production potential of the joint venture appear in different ways in accordance with the external and internal conditions of its functioning. Basically, they are determined by the following factors of the economic environment: the rate of development of scientific and technical progress, changes in demand, the state of the resource market and the internal characteristics of the production potential as a complex dynamic system [13-19].

\section{References}

1. https://works.doklad.ru/view/Xyhys4Hgktw/all.html

2. https://ecsn.ru/files/pdf/201101/201101_66.pdf

3. http: //luxis-it.ru/tekhnologicheskiy-potentsial

4. https: //econ.wikireading.ru/10552

5. https://econ.wikireading.ru/10552

6. http: //www.up-pro.ru/docs/analyticsdemo.pdf

7. https://www.nestro.ru/en/deyatelnost/proizvodstvennaya-sistema-ao-zarubezhneft/

8. T.V. Ignatova, T.P. Cherkasova, Econ. Vestn. Rostov. state un-that. 8.1, 109-116 (2010)

9. M.K. Starovoitov, P.A. Fomin, Anti-crisis and external management 2, 27-41 (2006)

10. P.I. Razinkov, The production potential of the enterprise. Formation and use, Monograph (TSTU, Tver, 2006)

11. A. Mottaeva, E3S Web of Conferences, 110, 02166, (2019) doi.org/10.1051/e3sconf $/ 201911002166$ 
12. V.B. Melekhin, Bulletin of the Dagestan State Technical University. Technical science 4(19), 108-112 (2010)

13. https://www.researchgate.net/publication/306041507_main_features_and_characteristi cs_of_production_potential_management_of_the_building_enterprise

14. Y.V. Morozyuk, A.V. Sharkova, I.A. Merkulina, O.N. Vasilyeva, Journal of Environmental Management and Tourism 8.3(19), 507-515 (2017)

15. I.A. Markina, A.V. Sharkova, M.Y. Barna, International Journal of Entrepreneurship 22(3) (2018)

16. S. Rakhimova, K. Kunanbayeva, L. Goncharenko, A. Pigurin, E3S Web of Conferences 110, 02154 (2019) https://doi.org/10.1051/e3sconf/201911002154

17. K. Kunanbayeva, A. Gorovoy, A. Butyrin, MATEC Web of Conferences 193, 05048 (2018) https://doi.org/10.1051/matecconf/201819305048

18. L. Akhmetshina, T. Pokrovskaya, D. Semernin, MATEC Web of Conferences 193, 05047 (2018) https://doi.org/10.1051/matecconf/20181930504

19. N.Tulebayeva, D. Yergobek, G. Pestunova, A. Mottaeva, Z. Sapakova E3S Web of Conferences 159, 01012 (2020) https://doi.org/10.1051/e3sconf/202015901012 